\title{
Oracy and the Educational Achievement of Pupils with English as an Additional Language: The Impact of Bringing 'Talking Partners' into Bradford Schools
}

\author{
Angie Kotler \\ Bradford Local Education Authority \\ Rupert Wegerif and Martin LeVoi \\ Open University, Faculty of Education and Language Studies, Milton Keynes \\ MK7 6AA
}

The relatively poor educational performance of some ethnically defined groups of children with English as an additional language (EAL) is a serious challenge for educators in the UK. In this paper we describe a research project designed to explore the hypothesis that this case of underperformance, like others, results from a mismatch between the registers learnt at home and those assumed in education. The method used was to offer extra support for those oral registers required for understanding in the classroom by providing trained adult 'talking partners' for young bilingual pupils. Sixty four pupils, aged between five and eight years, were given this additional oral language support and their progress in language and learning was then compared to that of similar pupils in the same schools. The findings show that extra sessions with adult talking partners made a real difference to their spoken English in an educational context and so to their engagement in education.

\section{Introduction}

The relatively poor educational performance of children from some ethnic minority groups is widely considered to be one of the most serious issues facing education in the United Kingdom today (see for example Ofsted, 1999). Government 'cohort studies' reveal a marked difference between the age 16 exam (GCSE) results of the majority and that of young people categorised as belonging to 'Pakistani' and 'Bangladeshi' communities (DfEE, 1999). Several different hypotheses could be put forward to explain this result. The study we describe in this paper was designed to test the view that this particular case of educational underperformance may be the product of a mismatch between the registers of language use learnt in the home and those required for educational success in the school. If this is the case the cause of the educational underperformance of these groups of children with English as an Additional Language (EAL) may well be the same as that for some groups of pupils with English as a first language (see for example Bernstein, 2000; Heath, 1983 and Mercer et al., 1999). This hypothesis was explored by evaluating the impact of extra coaching in those English oral registers that are assumed in education, particularly those that support reflection on language and 'reasoning' in an educational context. This was done through providing adult 'talking partners' in schools for young children in Bradford who 
had either Mirapur Punjabi (a dialect from Pakistan) or Sylheti (a dialect from Bangladesh) as their first language.

\section{The Need for Teaching Oracy}

All pupils in the UK sit national examinations in English, Mathematics and Science at age 7,11 and 14, at the end of what are described as Key Stages in the National Curriculum. The tests are commonly referred to as SATs (Standard Assessment Tasks). The UK Qualifications and Curriculum Authority insists that all pupils should be entered for these tests, unless they have recently arrived in the country and are considered by the school to need 'some time' to adjust. Implicit in this system is the notion that any pupil who has been in school for a reasonably normal length of time will stand as good a chance as any other of success in the tests, or rather is capable of achieving a certain level. This puts the burden of responsibility onto schools to differentiate provision in order to achieve some equity of outcome.

Bradford is a city in the UK with a large population of pupils with English as an additional language coming from Bangladeshi and Pakistani ethnic minorities. Currently such pupils attain scores at or around the national average in English tests at age seven (Key Stage 1) but their results plummet at age 11 (Key Stage 2). One hypothesis for this is that results at Key Stage 1 do not reflect a true picture of overall achievement in English and that they mask difficulties, which emerge later. For example, research in several countries (e.g. Geva, 1997), reveals that bilingual learners can adequately learn the rudiments of literacy with very little understanding of the target language. Comprehension and 'higher order skills', which are required at Key Stage 2 and beyond, are not possible without competence in oral registers supporting reflection and reasoning. However, there is little opportunity for EAL children to acquire this oral competence in the current curriculum. Observations in classrooms at the start of this project revealed that pupils rarely had the opportunity to listen to each other and were rarely able to initiate language use except to make basic requests. These findings are similar to those elsewhere. Cummins (2000) refers to research which shows that in over $50 \%$ of classroom interactions, pupils either say nothing or supply one-word answers. This is a pattern that clearly limits the use of language required for more complex learning. It is a major concern that opportunities to use language more productively in the classroom are found so rarely. It is even more worrying when this may be the only opportunity that a bilingual pupil has to learn the language she or he needs for educational success.

Courtney Cazden (1988), in her introduction to Classroom Discourse, writes that: 'The task for both teachers and researchers is to make the usually transparent medium of classroom discourse the object of focal attention'. and 'aspects of language in education are the result of non-deliberate, usually non-conscious choice at the moment of use'. Cazden draws attention, in her book, to the way teachers pay less attention to error in higher achievers, those whose language and experience match those of the teacher most closely. With these children, teachers attend to higher order skills of extending understanding, in other words true communication, which would occur between family members for example. Children who are more reticent, because they do not understand the rules in the 
classroom, get fewer opportunities to extend their learning, when clearly they are the ones who need more.

If the opportunities of EAL children to learn oral registers from teachers are limited, the same is true of their opportunities to learn from peers. Research by Mercer et al. (1999) as well as research in Bradford schools suggests that most classrooms still offer few opportunities for children to speak and listen to each other.

One possible response to this is to design situations that may help children learn to talk, learn to think and learn to learn in English. Cazden refers to a learning partner model in Israel where 'Joint study is considered the best way to ensure preciseness and clarity of thought' (Cazden, 1988). Tharp and Gallimore (1988) describe a model of teaching and learning in Hawaii which maintains a high focus on comprehension, so that teachers and learners alike understand what they are doing and why they are doing it. Cummins (2000) states that this in itself provided dramatic improvement in achievement of bilingual pupils.

Cazden asks that we try to distinguish between forms of speech which have academic value and those that do not, and then find ways of helping students to learn the ones that do. She writes: 'I assume that such strategies will require a combination of interesting contextualised activities plus occasional metalinguistic attention to language itself'. This is also borne out by the work of Palincsar and Brown (1986) who demonstrate the effectiveness of explicit oral teaching in group discussion around text. Mercer et al. (1999) describe lessons in how to use talk effectively leading to measurable improvements in both group and individual reasoning. Interestingly their oracy focused intervention appeared to have most effect on those pupils who were initially performing least well academically. This suggests that giving pupils access to the specific registers required for academic performance can help to combat negative assumptions that abound about groups of pupils who do not come to school already equipped in this way.

\section{Language Learning for Bilingual Learners}

The idea of being bilingual has different connotations; it has been shown to be an advantage when there is proficiency in at least one language before a new one is learned (Cummins, 1981). Proficiency in two languages often leads to ease of learning subsequent languages, because the understanding of how languages work develops along with the second language and rules can be applied. Gregory (1996) claims that bilingual learners notice the arbitrary nature of language earlier than monolinguals, who do not see the separateness of labels from their objects until much later. The difficulty with being an emergent bilingual, however, may be that the second language is being built upon shaky foundations; the academic language required at school may not have been learned at home so young children are learning new concepts in a new language. They have much more to do to assimilate concepts and the vocabulary for them simultaneously. The implication for educators is that they have more to do in terms of enabling these pupils to access the language needed for academic success.

In a situation where most of the pupils in a class, or indeed the whole school, as is the case in many schools in Bradford, share one language outside school and 
therefore have no need to develop even the social language in English, it must be the case that there is very little to build on in the classroom unless opportunities are provided for the use of a wide range of language functions. Verhoeven's (1987) research into the factors that influence successful second language learning concluded that the single most influential factor was the amount of contact with native-speaking peers. When there is little or no contact with native speakers, the teacher's task is greater, having to incorporate social functional language as well as more academic language.

A report commissioned by the UK Department for Education and Employment (DfEE) and carried out by the Open University (Blair \& Bourne, 1998) highlights a range of key features in schools where large numbers of bilingual pupils go on to achieve the national average or above throughout their schooling. One feature noted in all of the case studies was the careful attention given to oral language development. The report noted that training for teachers in how best to support their bilingual pupils had come through various routes but that newly qualified teachers did not feel equipped to deal with the challenges of a multilingual classroom. Cummins (2000) concurs with this. He says there has to be a

balance between, on the one hand extensive meaning-focused oral and written language input and use designed to promote problem-solving and higher-order thinking, and on the other, explicit formal instruction designed to develop linguistic and metacognitive awareness.

Other factors in successful schools, cited by both Cummins and the OU report, were effective leadership and affirmation of student and community identity. In this study we selected schools which we felt were to a large extent addressing the first two factors and were receptive to positively adapting teaching in order to empower all pupils.

\section{Links between Oracy and Literacy}

Research in Canada carried out by Esther Geva (1997) has shown quite clearly that learning to read in a second language is a complex matter and that we can make no simplistic assumptions about the role of the first language or the relation between the two languages in which the child is operating. Her study of a group of Punjabi speakers in Toronto indicated that learning the basics of reading in a second language is not dependent on oral proficiency. Word recognition and decoding skills can be and frequently are learned in a second language without any deeper understanding of the target language. So we can be led to think that pupils reading successfully in a second language at age seven (Key Stage 1) are well on the way, but tests of comprehension, inference and deduction come later. Further evidence from the studies on various groups in Canada reveals that these 'higher order skills' are not possible to achieve without understanding of the language. Geva concluded, ' word-based reading skills are less dependent on the attainment of oral language skills than discourse processing'. In addition Geva found that, while groups of pupils with English as first language (L1) and groups with English as a second language (L2) had comparable results on tests of written English, there was a significant difference between these groups on tests of oral competence with 'a clear advantage for the L1 children'. 
A small-scale study in Bradford (Kotler, 1997) helps to demonstrate how this discrepancy between written and oral English test results can come about. In this study two readers, both aged seven, one English L1 and one English L2 and seemingly reading the same level of text, process the same text in very different ways. The English L1 pupil struggles continuously to make sense of the words, stops and asks or exclaims if he cannot. The English L2 pupil continues, regardless of errors which change the meaning or the syntax of the text, relying heavily on identification of words he recognises, which are scattered throughout the passage. The following extract is a typical illustration of this:

They the hand him squeeze a giant squeeze (Child)

Then they heard him sneeze a giant sneeze (Text)

The intervention of the teacher ( $\mathrm{T}$ in the transcript), drawing the child's attention to semantics and syntax, not word error, helps him to seek clarification by learning strategies he can use not only on this particular book but on future occasions. She teaches him how to use the language to think and problem solve as he reads, as in the following example:

Suddenly the giant couldn't and couldn't and couldn't.

Suddenly the giant coughed and coughed and coughed.

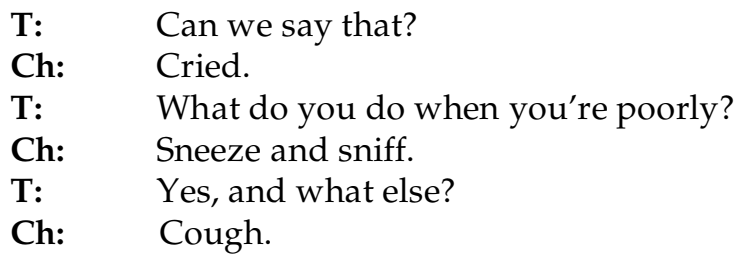

This research in classrooms leads to the conclusion that the apparent success of many bilingual pupils at age seven (Key Stage 1) masks the fact that many children are still at a very early stage of oral language acquisition and so pupils progress to the challenges of the next stage of the curriculum (Key Stage 2) on very shaky foundations. Although it is impossible to state at this stage that this is the sole reason for the underachievement of so many pupils in Bradford - a combination of factors is always involved in such complex situations - it indicates that we should certainly investigate the role of oral language further, both in relation to developing literacy and to cognitive growth.

\section{Principles Guiding the Development of the Talking Partners Project}

The findings of research on teaching oracy referred to above argue strongly for the importance of establishing clear structures so that pupils know what to expect and when, as well as modelled language in context as the tool for learning. Our intention in this project was to build on the findings of this research, particularly that of Mercer and Wegerif (e.g. Mercer, 1995; Mercer et al., 1999; Wegerif et al., 1999) to develop a model for classroom interaction. In summary, we felt we needed to establish:

- opportunities for extended talk; 
- situations which require collaborative talk;

- ground rules for task oriented talk, e.g. waiting and turn-taking;

- support, guidance and encouragement but not dominance by the adult/teacher;

- contexts which build on prior experience and enable new learning to occur.

Further related pedagogical principles can be derived from the findings of research on effective teaching for bilingual pupils. The findings of the OU report referred to above have also been borne out in other contexts. Wong-Fillmore (1985) found that Spanish-speaking pupils in California attained more highly when they were in schools which provided structured language lessons, where the target language was used frequently in clear contexts and where the teacher's talk:

- focuses on real communication;

- is presented in known contexts;

- has heavy message redundancy;

- uses mainly simple structures;

- uses repetition of structures;

- uses elaboration of pupils' utterances.

Cummins (e.g. 2000) has long maintained that language and content will be acquired most successfully when students are challenged cognitively but also provided with the contextual and linguistic supports required for successful task completion. Gibbons (1995) describes a way of working that she calls 'Guided Reporting', which is very like Talking Partners in that both adults and pupils use a set of prompts to support the reporting process. The following excerpt from a transcription of a Talking Partners session with a group of six- and seven-year-old EAL pupils illustrates how this works:

Teacher:

(pointing to a card with the prompts: 'Who did you work with? What were you doing? How did you do it? ('First of all ... After that ... Next ... Finally ...'.) Did you have any problems? What did you do to solve them? What did you like about the activity?) OK Nadim, do you want to have a go at telling us about your experiment?

Nadim: We was looking at water.

Teacher: $\quad$ Yes, we were looking at water and we used a special name; can you remember the special name?

Nadim: $\quad$ Liquids.

Teacher: $\quad$ Yes, well done. Now look at the card and try to tell us what you did.

Nadim: $\quad$ I worked with Sohail ... we put the pink liquid in the square box ... it looked like a swimming pool!

Teacher: $\quad$ Yes, it did look like a swimming pool! Was it a square or a rectangle?

Nadim: $\quad$ It was a rectangle.

Teacher: $\quad$ Yes, good. Carry on, what happened next?

Nadim: $\quad$ Next we poured the pink liquid into the ... the round container and and and some water spilled on the table ...

Teacher: $\quad$ Yes, it spilled and it did make a bit of a mess, didn't it! 
Nadim:

(laughing) ... it spilled and we had to get a cloth. I liked it because we saw they was the same size!

The teacher went on to help all the pupils clarify their understanding of conservation and a lively discussion ensued. Several pupils who would not have attempted to put their observations into words were given the confidence to try with the prompts to support and guide their thoughts and constructions.

We conclude from this that while opportunities, turn-taking, support and encouragement are essential, more repetition and contextual support may often be needed where language is new to the learners. The aim of using this methodology is not only to help pupils complete individual tasks, but to equip them with strategies to use elsewhere.

A model for the development of an educational programme to address the needs of bilingual learners was provided by the success in Bradford of the Better Reading Partnership. This project provides training and accreditation for additional adults who work in schools and deliver intensive reading sessions to targeted pupils. Evaluation has shown that this can increase pupils' reading ages by an average of six months over a ten week period and leads to increased awareness of how children learn to read amongst teachers, nursery nurses, classroom assistants, parents, business partners and other volunteers.

The Talking Partners project was developed on the model of the Reading Partners scheme and based on the pedagogical principles described above derived from the literature.

\section{The Programme}

For each activity, we wanted the adults to consider not just what they were going to do, but also the vocabulary they wanted the children to use, the language structures required and the overall function or area of language they were working in. An example of planning for an activity might look something like this:

Activity

Barrier game

\section{Language function}

Giving partner

instructions, following instructions, describing position

\section{Language structures}

Put the ... on top,

next to, underneath

\section{Vocabulary}

Triangle,

rectangle,

blue, red,

yellow,

We aimed to ensure that all activities suggested to adults operating the Talking Partners programme were to be problem-solving activities which had a clear context and which stretched the learner. The activities all required interaction with both the adult and the other pupils in the small group, in which everyone had to give and be given sufficient time to participate as fully as they could.

The adults were encouraged to support the children's approximations and extend these where appropriate. They were asked to plan appropriately and to observe and reflect on the children's performance after each session. An observation focus had to be chosen for each session or at the least each week (comprising the three sessions) and an observation checklist, based on the main objectives of the programme (see below), was used over the ten-week period to note where changes in the children's competencies had occurred. To make this simple, three 
colours were used: red for where behaviours did not occur, green for where they began to occur with support, blue for where they occurred independently.

\section{The training programme}

Previous experience has shown that, in order to reap the rewards of additional school programmes, there is a need for quality training, school support and clear guidelines for working. The training programme for partners incorporates the following messages:

(1) Lesson structure is essential to ensure clarity of purpose and pace of learning.

(2) A positive atmosphere must be created so that pupils feel safe to become 'risk-takers' in using new language. In order to do this, specific praise and prompts will be used.

(3) Observation and analysis of pupil behaviour is at the heart of all decision-making; planning is informed by what we perceive the pupils are able to do.

(4) Continuous assessment is essential but must also be manageable.

(5) A support network will be established, both in school and centrally, follow-up training will be provided and accreditation will be offered.

(6) Resources for Talking Partners will be provided initially, with ideas and suggestions for how to increase the school supply of these.

The training course therefore was a combination of theory and practice, incorporating two observation sessions through the two-way screen, where observation was guided by a trainer and subsequent discussion led participants to understand the aims and objectives of the activities and the behaviour of the pupils in terms of their speaking and listening. Participants understood that in Talking Partners, the objectives for the pupils are:

- an expectation that they will understand and communicate;

- confidence and willingness to take risks;

- flexible control over a range of strategies;

- increasing independence;

- an ability to access and use talk effectively in contexts relevant to the National Literacy Strategy and throughout the curriculum.

More specifically, in terms of the content of the programme, objectives for listening and speaking were drawn up and referred to throughout the training days.

\section{Objectives for listening}

(1) To develop active listening, i.e. the expectation that you are listening because you will act on what you have heard.

(2) To monitor understanding.

(3) To take action where necessary, using strategies such as:

- indicating the need for clarification;

- indicating what needs confirming or clarifying;

- formulating questions for speaker. 


\section{Objectives for speaking}

(1) To respond, e.g. to express ideas or opinions based on new information or to challenge others' opinions.

(2) To develop overall organisation of spoken text extended stretches of language, e.g. reports, story retellings).

(3) To develop explicitness and an awareness of the needs of the listener, creating a shared context.

(4) To develop accurate use of a wider range of grammatical structures.

(5) To support development of specific vocabulary appropriate to the focus for communication.

As noted above, partners were asked to monitor pupils' progress according to these objectives, noting whether these behaviours were becoming more consistently apparent across a range of activities.

The following example shows a child who in a group of three pupils in a Talking Partners session attempts to relay her 'news' for the first time:

Alisha: On the weekend I went Pakistan.

Teacher: Did you go to Pakistan?

Alisha: No.

Teacher: Did you go to the airport to see your Grandma go to Pakistan? Alisha: Yes!

Six weeks later in a similar session:

Alisha: $\quad$ On Saturday I went to town with my mum and she bought some leggings and a jumper.

A key feature of the Talking Partners work is that partners work with a group of three children. This was very important, as a major aim of the work would be to encourage and develop peer discussions. The next extract shows an example of such a discussion in the context of a barrier game; two pupils on one side of the barrier, one on the other, playing a game using coloured letters and a grid:

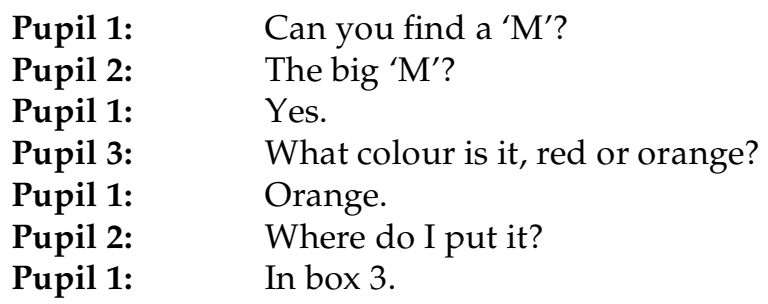

Another significant feature is the provision of resources in order to scaffold the tasks. It was necessary to devise activities that would elicit extended talk between pupils. The researchers provided samples of activities for all six themes to be addressed in the programme. Often, photocopies of pictures from stories could be used to aid sequencing of stories, a simple grid was designed for barrier games and a collection of puppets and small figures was assembled. These were very popular with the children and some lively spontaneous talk developed from them, as in this girl enacting Little Red Riding Hood with a puppet: 
Girl: (holding and talking to puppet of Red Riding Hood) You have to go to Granny's.

Puppet: Why?

Girl: Granny is ill, now go wash your dirty face!

Once samples had been provided and activities tried and tested, the schools collected and organised resources for Talking Partners in a very short time. Resources were kept centrally in schools so that everyone had access to them. In this way successful activities were often carried over into classroom practice. Although this shows the value of the activities, it may have affected the results of the control children. In retrospect it was a mistake from a research point of view to have control and experimental groups in the same schools.

A third and very important feature of the Talking Partners programme is the provision of prompt cards. Because a major aim of the programme is to increase pupils' ability to monitor their own understanding and to increase independence in developing oral text, it was necessary to provide frameworks for this, both for the adult partners to refer to and for the pupils themselves, as seen in the Teacher?Nadim exchange above. One set of prompts was not sufficient for all the different areas of activity. Prompt cards were made for each activity and at different levels; these varied in colour according to language function and coded on the reverse side to match the activities in the booklet. There were 12 cards in all, given to the trainees during the training days. These included a white card listing speaking and listening courtesies. For some groups this was a very helpful place to start!

\section{The Measures Used}

After pilot testing using a random sample of 49 pupils, it was decided to use three tests: the British Picture Vocabulary Test, using the version standardised on an urban EAL population; the Record of Oral Language - Levels Sentences (Clay, 1993, adapted with kind permission of Marie Clay); and the Renfrew Action Picture Test (Renfrew, 1997). Three tests were decided upon, because they measure different aspects of language development, receptive vocabulary, control of standard grammatical forms and expressive ability (both information and grammar). No one test measures every aspect of oral language and ease of administration was an important consideration. All tests are a compromise between naturalness and efficiency, so a range of assessments, both quantitative and qualitative was considered essential for a pilot programme.

The Record of Oral Language - Levels Sentences requires children to repeat increasingly complex sentences and a score is given for the number of accurate responses. This test is not standardised and has no age-equivalent scores. There is not, therefore, a scale of progress. However, using this test with the 49 sample pupils produced some interesting findings; for example, as the complexity of the sentences increased, pupils attempted to preserve meaning at the expense of grammar, but there was a clear point where the complexity of the sentence structure prevented access to meaning and then pupils were unable to respond. There is a parallel here to younger children learning their first language, where they usually produce key ideas in condensed form. There is also a parallel with early reading acquisition, which again warrants further investigation. 
The Renfrew Action Picture Test is a standardised test providing separate raw scores both for information and for grammar. It has the advantage of being very simple to administer, comprising ten picture cards with a question on the reverse to prompt the child to describe the picture. The main disadvantage of this assessment was that some of the pictures included scenes unfamiliar to the target children, but this would be the same for them all.

Qualitative data were also gathered. The adult partners were asked to keep an observation record of the changes in children's speaking and listening behaviours over the ten-week programme, using an observation record form based on the aims of the programme outlined above. Class teachers and school co-ordinators were also asked to fill in a questionnaire about the effects of the Talking Partners programme.

\section{Design of the Evaluation of Talking Partners}

Seven schools were selected for the study. Six of these were in an inner city area of Bradford, where almost $100 \%$ of the pupils are learning English as an additional language. The pupils in five of these schools speak mainly Mirpuri Punjabi at home and in one they are mainly from Sylheti-speaking families. The seventh school is unusual in the Bradford context, having a mixed population, approximately half the pupils being Sylheti speakers and the other half having English as a first language. All seven schools have a high proportion of pupils entitled to free school meals and had low English results at age seven.

The focus of the programme was on pupils, aged five to eight, in school years 1 to 3 . Twenty-five partners were trained and they each subsequently worked with a group of three children for ten weeks, three times a week for 20 minutes. The training was carried out in September, at the beginning of the school year; the programme then ran for the autumn term. Pretests were all conducted in September and post-tests were all conducted in December. In summary:

- A two-day training course was delivered to 25 school-based adults.

- A teacher was also trained and had the additional role of establishing the programme in school and supporting partners.

- Six children were selected from the average band in their class, three of whom were assigned to the programme and the other three were used as controls.

- Partners worked with programme children three times a week for 20 minutes for a period of ten weeks.

- The use of specific prompts, praise and frameworks was paramount.

- All children were assessed pre- and post-intervention by the researchers, who were able to test 'blind'.

For the evaluation seven schools were asked to select a group of six pupils from the average band in their year 1,2 and 3 classes. Some schools also chose to work with groups of children in reception or year 4 classes, therefore reaching the whole range of the first school. The children were assigned randomly into target or control groups, three in each. All pupils were tested (blind) by the researchers using the BPVS, Renfrew Action Picture Test and Record of Oral Language - Levels Sentences. They were then tested again (blind) after the ten-week Talking Partners programme. In total we collected full pre- and 
post-test data on 64 target pupils in years 1,2 or 3 (age five through to eight) and 63 control children.

\section{Results}

\section{Qualitative results}

All class teachers noticed that the Talking Partner children had gained confidence in speaking, some only in small groups but others within whole class discussions, and that they were more attentive and willing to participate. Many comments related to children's increased attempts at extended discussion around topic work; perhaps the children felt that they now had permission to talk more. One headteacher included writing samples from children to show improved understanding of text structure that had transferred to their written work. This shows that the oral composition that the pupils learn, in supported and structured contexts, is a skill that can be carried across into other specific academic tasks. Gibbons (1995) explained that 'Guided Reporting' acted 'as a bridge' between reading and writing and that is precisely what we felt about the purpose of Talking Partners. It provided the additional opportunity for pupils for whom the language and content may be new, to take possession of the ideas and learn how to express them.

Another positive outcome of the programme was that because of the clarity of the structure, both adults and pupils began to feel more at ease with each other and to build better relationships. They felt more able to ask each other questions, as barriers came down and assumptions were replaced by success.

On the negative side, some teachers expressed concern that the children withdrawn for Talking Partner sessions had disruptions to other lessons and that staff who were working as partners could not be supporting within the classroom at the same time. These organisational issues always arise when decisions have to be made about the best provision for children at any one time and when teachers are under tremendous pressure to cover the curriculum. It addresses the fundamental issue of whether schools can manage to adapt the curriculum to meet the needs of all pupils.

The records kept by the Talking Partners themselves indicated that they had observed clear progress over the ten weeks in relation to the observation criteria. Most pupils had improved in ability to listen attentively and take turns as a speaker, generate questions and incorporate key elements of the various frameworks in their language.

\section{Quantitative results}

From a statistical point of view this study took a random sample of English schools, in which a random sample of children were nested. Clark (1973:348) and Winer (1971:365) tell us that in such a design, the analysis should collapse over the children in each school and analyse the data with schools as the random

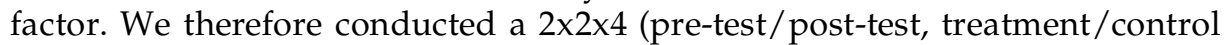
and school year group) multivariate analysis of variance (MANOVA) over the four dependent variables (Renfrew Information, Renfrew Grammar, Record of Oral Language and British Picture Vocabulary Test). The crucial test is whether there was an interaction between the two independent variables pre- and 
post-test with treatment and control conditions: if the Talking Partners treatment had an effect pre- to post-test it should be different for the two groups. The MANOVA was significant for this interaction (Rao's $R[4,27]=3.13, p<0.05)$ : the three-way interaction was not significant (Rao's $R<1$ ). Following this significant result, the result was examined by looking at the univariate ANOVA's on each dependent variable individually. Figues 1 to 4 illustrate that the results of the four quantitative comparisons on measures of oral competence show that the Talking Partner children had increased their scores in relation to the matching control children. The results of an analysis of variance across seven schools and three years comparing the target and control groups and the pre- and post-scores

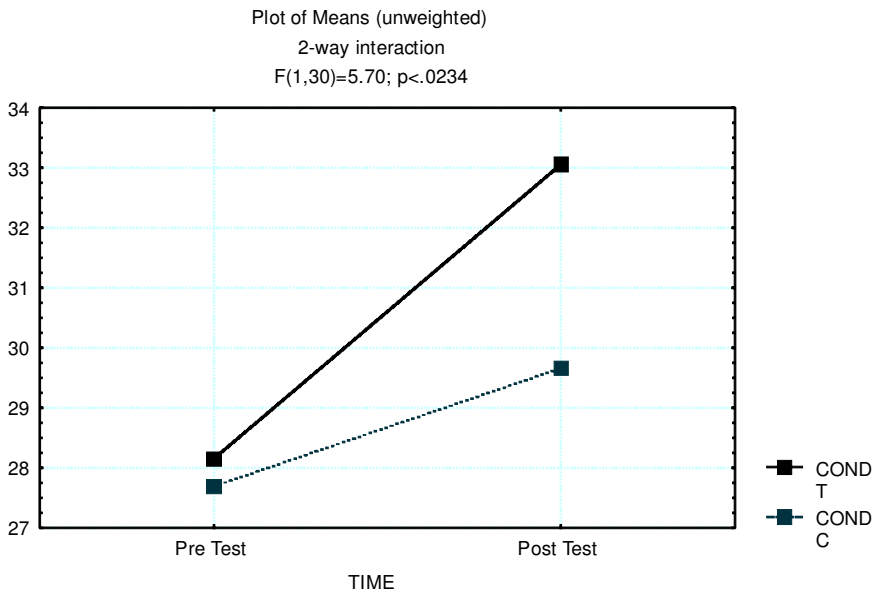

Figure 1 Renfrew information

Plot of Means (unweighted)

2-way interaction

$F(1,30)=3.61 ; p<.0670$

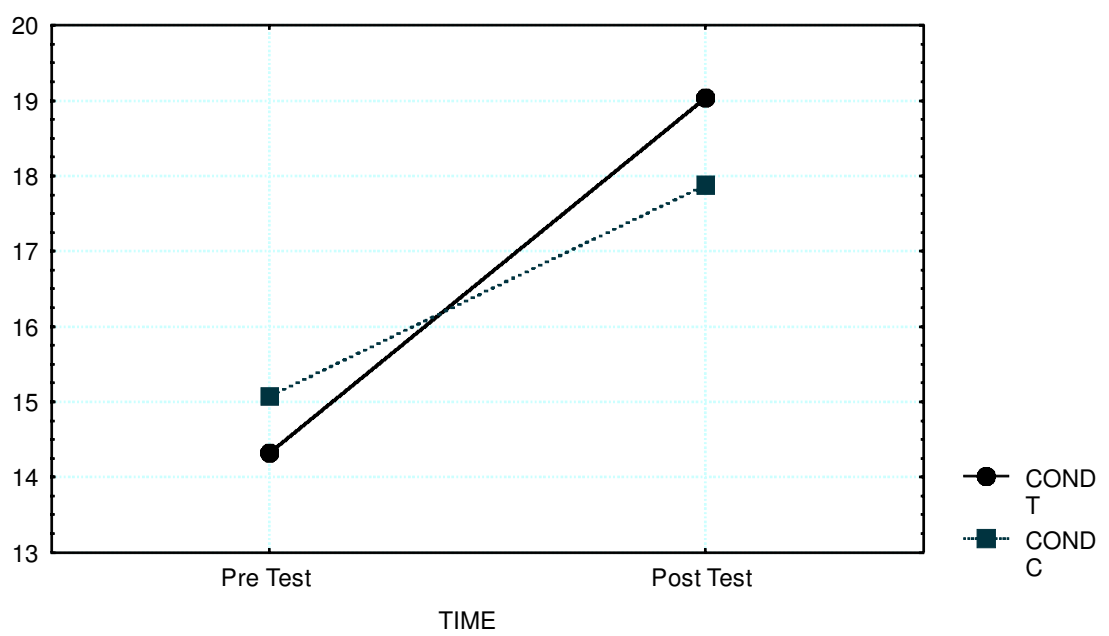

Figure 2 Record of oral language 
Plot of Means (unweighted)

2-way interaction

$F(1,30)=3.48 ; p<.0720$

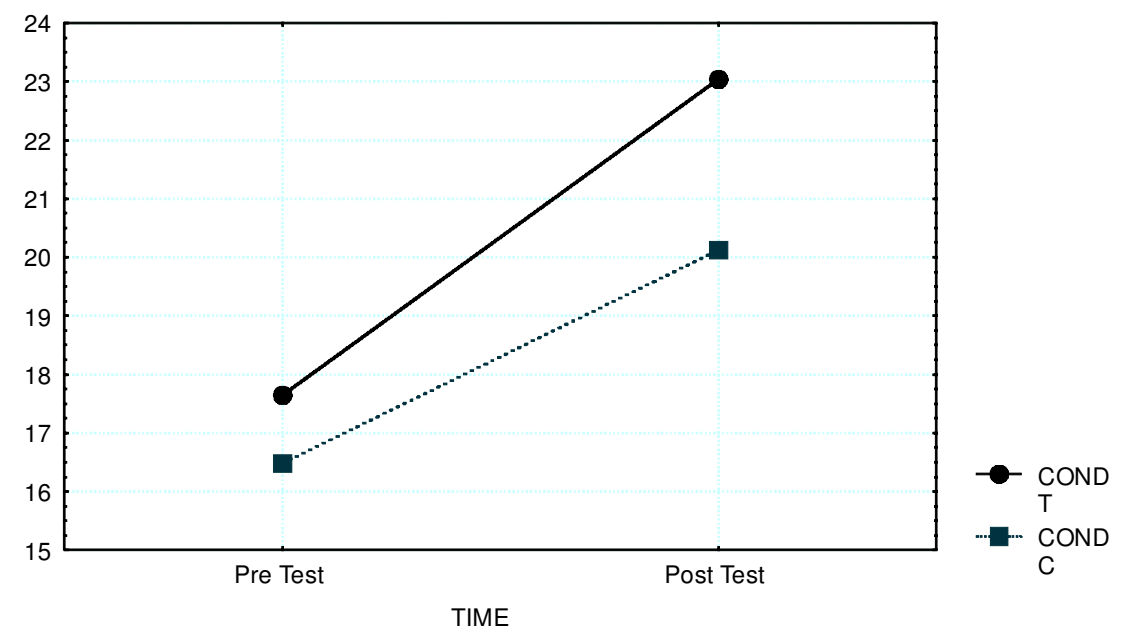

Figure 3 Renfrew Grammar

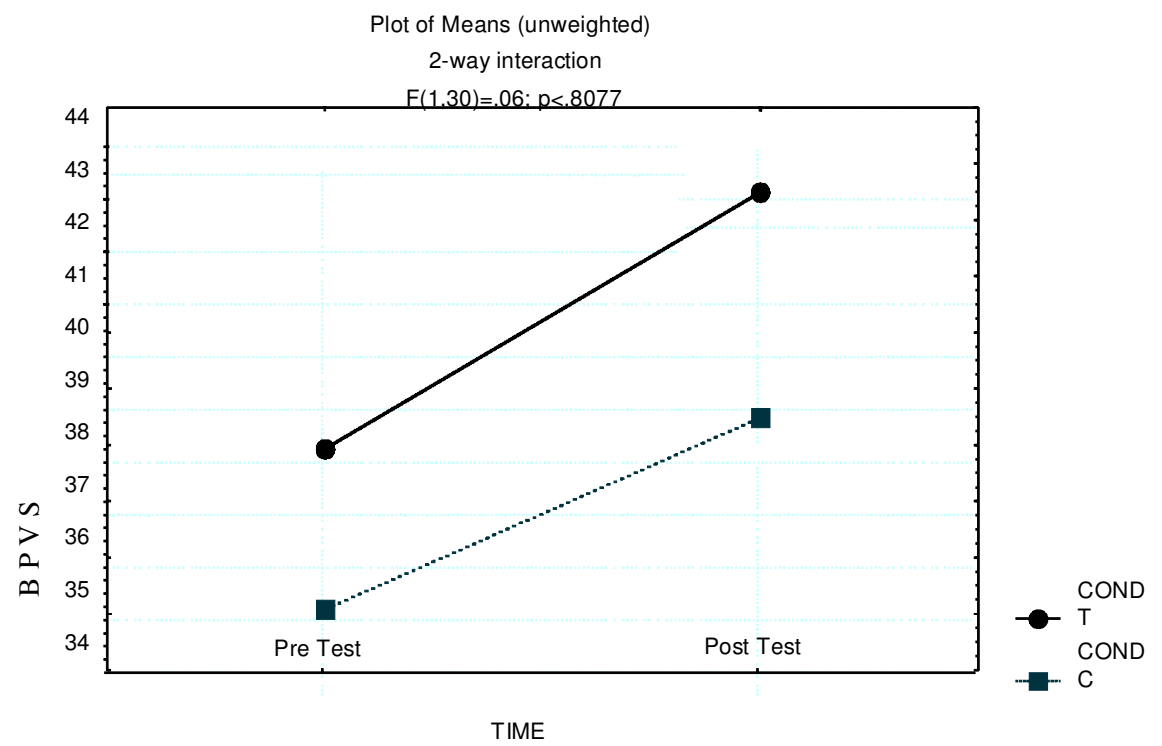

Figure 4 British Picture Vocabulary Test 
in each case is also given in the figures. This shows a statistically significant interaction $(p=0.02)$ between target and control in the scores of the Renfrew Information test (Figure 1).

\section{Discussion of these results}

These tests were taken over the relatively short period of ten weeks. It is interesting then that the scores of the control group all increase although never as much as those of the target groups. One possible reason for this is the 'leakage' effect described earlier occurring through teachers and classroom assistants sharing good practice in each school. Having matching control groups in the same schools as the target groups was a weakness of the research design.

However, despite the short time period, the possible 'leakage' effect and the relatively small number of pupils tested (64 target to 63 controls), it is striking that a statistically significant improvement in oral competence was achieved overall and for the Renfrew Information measure. The feedback from the teachers and observations in the schools suggest that this improvement in measures of oral competence is also complemented by a greater engagement in classroom work across the curriculum. The results therefore confirm the value of our teaching approach to addressing the problem of the educational underachievement of these specific groups of children.

\section{Summary and Conclusions}

The aim of this research project was to see if an intervention based on what we know about the way children learn language could make a significant difference to EAL learners' control over oral language, particularly in relation to literacy learning. Results from a range of assessments, but particularly from the Renfrew Action Picture Test, show that it is possible to accelerate such learning.

Talking Partners provides an early intensive and focused intervention, by increasing adults' awareness of how to observe what pupils bring to the task and of ways to create learning contexts able to accelerate their learning. This programme was developed from what we have learned from other successful intervention programmes such as Reading Recovery and the Better Reading Partnership, about the way children learn and how to facilitate that learning in school. Our experience with Talking Partners raised three key points:

- that interventions of this type need to be supported by whole school teams if the effects are to be sustained;

- that the attainment needs to be measurable and

- that the staff training needs to involve reflection on practice in a way that raises awareness and so leads to changes and improvements in that practice.

It is impossible to say, from one small-scale study, that it is the combination of these factors that has led to the success of the programme. As Cummins (2000) says:

Every interaction between teachers and pupils can be analysed from multiple perspectives (how effective is it pedagogically, what conception of 
language is implicated in the instruction, what messages related to status and power are being communicated, etc.)

It is possible that the focused attention of one adult for three sessions a week made a significant difference. It is possible that the prompt cards alone would have had a significant effect. Perhaps just raising the issue of additional focused language support for certain pupils with the school teams would have led to similar outcomes. However, comparative studies that have attempted to isolate such variables and from which we drew our design, suggest that it is a combination of these factors which leads to successful outcomes. Talking Partners provides this combination. It shows that trained adults can be helped to realise what pupils need in order to be able to learn effectively in a mainstream classroom and that pupils can be helped to see how to interact effectively. We believe that through this programme both adults and pupils are empowered.

This research focused on young bilingual learners at schools in Bradford, England, but we would claim that the principles of this work are equally applicable to all young children entering learning institutions. Teachers who have operated Talking Partners with English first language pupils have reported that they have made similar gains to the bilingual pupils. Although our quantitative research findings looked only at language measures we would also claim, following the work of Mercer, Wegerif and Dawes, that through teaching oral competence we are providing pupils with the essential tools that they need to engage with and make sense of the education system and so to achieve more within it. This suggests that the success of the programme could possibly be explained by the fact that Talking Partners helps pupils to develop the specific registers required for academic success, registers which are less likely to be acquired outside of school by some groups of pupils.

\section{Correspondence}

Any correspondence should be directed to Dr Rupert Wegerif, Faculty of Education and Language Studies, Open University, Milton Keynes, MK7 6AA (r.b.wegerif@open.ac.uk).

\section{References}

Bernstein, B. (2000) Pedagogy, Symbolic Control and Identity: Theory, Research, Critique (revised edn). Lanham, MD: Rowman and Littlefield Publishers Inc.

Blair, M. and Bourne, J. (1998) Making the Difference: Teaching and Learning Strategies in Successful Multi-ethnic Schools. Open University for the DfEE. London: HMSO.

Cazden, C. (1988) Classroom Discourse: The Language of Teaching and Learning. London: Heinemann.

Clark, H.H. (1973) The language-as-fixed-effect fallacy: A critique of language statistics in psychological research. Journal of Verbal Learning and Verbal Behaviour 12, 335-359.

Clay, M.M. (1993) Reading Recovery: A Guidebook for Teachers in Training. London: Heinemann.

Cummins, J. (1981) The role of primary language development in promoting educational success for language-minority students. In Schooling and Minority Students: A Theoretical Framework. Los Angeles: Evaluation, Assessment, and Dissemination Center, California State Department of Education.

Cummins, J. (2000) Language, Power and Pedagogy: Bilingual Children in the Crossfire. Clevedon: Multilingual Matters. 
DfEE (1999) Youth Cohort Study: The Activities and Experiences of 16 and 18 Year Olds in England and Wales 1998. London: HMSO. (http://www.dfee.gov.uk/news/99/152.html).

Geva, E. (1997) Issues in the development of second language reading: Implications for instruction and assessment. Paper presented at the International Workshop on Integrating Literacy, Research and Practice, March 13-14, London.

Gibbons, P. (1995) Learning a new register in a second language: The role of teacher/student talk (Working Paper no.1). Sydney: University of Technology.

Gregory, E. (1996) Making Sense of a New World: Learning to Read in a Second Language. London: Paul Chapman Publishers.

Heath, S.B. (1983) Ways with Words: Language, Life and Work in Communities and Classrooms Cambridge: Cambridge University Press.

Kotler, A. (1997) Does an interactive reading model look the same for a bilingual and monolingual learner. Unpublished report. Bradford LEA.

Mercer, N. (1995) The Guided Construction of Knowledge: Talk Amongst Teachers and Learners. Clevedon: Multilingual Matters.

Mercer, N., Wegerif, R. and Dawes, L. (1999) Children's talk and the development of reasoning in the classroom. British Educational Research Journal 25 (1), 95-111.

Ofsted (1999) Raising the Attainment of Ethnic Minority Pupils: Overview and Key Issues. London: HMSO.

Palincsar, A.S. and Brown, A.L. (1986) Interactive teaching to promote independent learning from text. The Reading Teacher 39 (8), 771-777.

Renfrew, C. (1997) Action Picture Test. London: Winslow Press Ltd.

Tharp, R. and Gallimore, R. (1988) Rousing Minds to Life. Cambridge: Cambridge University Press.

Verhoeven, L. (1987) Literacy in a second language context: Teaching immigrant children to read. Education Review 39 (3), 123-145.

Wegerif, R., Rojas-Drummond, S. and Mercer, N. (1999) Language for the social construction of knowledge: Comparing classroom talk in Mexican pre-schools. Language and Education 13 (2), 133-151.

Winer, B.J. (1971) Statistical Principles in Experimental Design. New York: McGraw-Hill.

Wong-Filmore, L. (1985) When does teacher talk work as input? In E. Bialystock (ed.) Input in Second Language Acquisition (pp. 46-69). Cambridge: Cambridge University Press. 